\title{
PEMETAAN PERMASALAHAN DALAM PELAKSANAAN PAGELARAN HEMAN KA BUDAK DALAM PENINGKATAN KEBANGGAAN BUDAYA SUNDA
}

\author{
Mirana Hanathasia ${ }^{1}$, Suharyanti ${ }^{2}$, Ari Kurnia ${ }^{3^{*}}$ \\ Program Studi Imu Komunikasi, Universitas Bakrie, Jakarta, 12960, Indonesia \\ E-mail: ${ }^{1}$ mirana@bakrie.ac.id, ${ }^{2}$ suharyanti@bakrie.ac.id, ${ }^{3}$ ari.kurnia@bakrie.ac.id* \\ DOI: https://doi.org/10.36782/ijsr.v1i02.10
}

\begin{abstract}
Abstrak
Pelestarian kebudayaan lokal dapat dilakukan dengan berbagai kegiatan, salah satunya adalah pertunjukan seni. Melalui pagelaran Heman ka Budak yang dilakukan oleh Dinas Pendidikan dan Pendidikan (Disdikbud) Kabupaten Kuningan, Jawa Barat menghasilkan sejumlah kegiatan bertema seni dan budaya yang rutin dilakukan setiap minggunya di acara Car Free Day. Tujuan dari Pengabdian kepada Masyarakat ini untuk meningkatkan kebanggaan Budaya Sunda oleh masyarakat khususnya remaja dan dukungan dari banyak pihak dalam melestarikan kebudaya lokal. Dalam menghadapi permasalahan kurangnya kesadaran masyarakat dalam melestarikan budaya lokal, sejumlah evaluasi dilakukan salah satunya adalah melalui teknik Focus Group Discussion (FGD), yang dilakukan bersama kepala Disdikbud dan sejumlah seniman yang kerap mengikuti kegiatan Heman ka Budak. Dalam FGD tersebut, kegiatan mingguan Heman ka Budak menghadapi sejumlah kendala dalam tujuan melestarikan budaya Sunda ini. Selain belum mendapatkan dana untuk mendukung kegiatan, seperti uang transport para pengisi acara, konsumsi, dan biaya teknis lainnya, penggunaan media massa sebagai sarana promosi dan informasi juga hanya menggunakan media sosial Facebook dan Instagram. Tidak ada keterlibatan media massa lokal maupun nasional juga sponsor berupa pendanaan atau pun produk, sehingga kegiatan pelestarian budaya lokal ini belum menjadi perhatian publik secara massa, hanya bermain di lingkungan Kabupaten Kuningan, Jawa Barat. Keterlibatan remaja dalam kegiatan ini hanya sebagai pengisi acara, tidak sejauh mereka melakukan promosi dan publikasi sebagai wujud kebanggan terhadap kesian budaya lokal.
\end{abstract}

Kata Kunci: heman ka budak, budaya sunda, media massa

\begin{abstract}
Preservation of local culture can be finish with various activities, which is an art performance. Through the heman ka budak performance, conducted by Dinas Pendidikan dan Budaya (Disdikbud) of Kuningan District, West Java, it produces of arts and culturalthemed activities that are routinely every week at the car free day event. The purpose of this social responsibility is to increase the pride of sundanese culture by the community, especially teenagers and the support of many parties in preserving local culture. In dealing with the problem of lack of public awareness in preserving local culture, evaluations through the focus group discussion (FGD) technique, which of Dinas Pendidikan dan Budaya (Disdikbud), artists as a participated in the activities of heman ka budak. In the $F G D$, heman ka budak activities faced of obstacles in the preservation this sundanese
\end{abstract}


culture. In addition to not getting funds to support activities, such as transportation costs for performers, consumption, and other technical costs, mass media to promotion and information also only uses facebook and instagram. There is no involvement of local and national mass media as well as sponsors of funding or products. So, local cultural preservation activities have not become a mass public concern, only held in the Kuningan District, West Java. The involvement of young people in this activity is only as a filler, not as long as they do promotions and publications as a pride towards the local culture.

Keywords: heman ka budak, sunda culture, mass media

\section{Latar Belakang}

Bagi sebagian besar masyarakat, arti kebudayaan seringkali terbatas pada sesuatu yang indah seperti misalnya candi, tarian, seni rupa, seni suara, sastra, dan filsafat. Budaya menurut KBBI (Kamus Besar Bahasa Indonesia) adalah pikiran, akal budi atau adat-istiadat. Secara tata bahasa, pengertian kebudayaan diturunkan dari kata budaya yang menunjuk pada pola pikir manusia. sementara budaya merupakan sebuah nilai kearifan lokal yang masih ada dipertahankan oleh masyarakat yang masih memiliki tingkat kepercayaan yang kuat. Melville J. Herkovits menyatakan, kebudayaan merupakan sesuatu yang bersifat superorganik, karena bersifat turun temurun dari generasi ke generasi berikutnya, walaupun manusia yang ada didalam masyarakat senantiasa silih berganti disebabkan kematian dan kelahiran (Soerjono soekamto, 2006).

Salah satu budaya yang berakar dalam kehidupan masyarakat Kuningan adalah "Heman ka Budak". Dalam bahasa Sunda "Heman ka Budak" terdiri dari dua kata. Dalam kamus bahasa Sunda "Heman" yang berarti sayang serta suka memberi dan "Budak" yang berarti anak-anak. Maka, dapat disimpulkan bahwa Heman ka Budak adalah kegiatan pagelaran seni yang dilakukan oleh tokoh-tokoh budaya Kuningan dengan bantuan Dinas Pendidikan setempat yang bertujuan untuk mengembangkan dan melestarikan budaya Kuningan yang berasal dari tiap-tiap sekolah dan umum yang ada di Kuningan, Jawa Barat.
Gelar budaya "Heman Ka Budak" berawal dari adanya ketertarikan dari Kepala Bidang Dinas Pendidikan dan Kebudayaan Kabupaten Kuningan, Dodon Sugiharto. Kecintaannya terhadap budaya Sunda dan keinginannya melestarikan sejumlah kesenian, ia membuat konsep acara yang dilaksanakan rutin setiap hari Minggu di Car Free Day di Kabupaten Kuningan, Jawa Barat. Berdasarkan hasil wawancara dengan beliau pada 30 Juni 2019, ia menjelaskan bahwa ia melihat potensi siswa yang tersebar di seluruh satuan pendidikan di Kuningan (Paud, TK, SD/MI, SMP/ MTs, SMA/SMK, perguruan tinggi) dan sanggarsanggar seni untuk berkegiatan di tengahtengah masyarakat. Selanjutnya ia memberikan wadah atau ruang melalui kegiatan Heman ka Budak setiap minggunya dalam Car Free Day.

\section{Rumusan Masalah}

Permasalahan yang terjadi dalam pagelaran mingguan Heman Ka Budak adalah bagaimana pemetaan menyelesaikan masalah dalam upaya melestarikan budaya lokal bagi remaja. Karena nila-nilai kearifan lokal sesungguhnya masih ada, hanya saja peran masyarakat dalam upaya menerapkan nilai-nilai budaya dalam sejumlah kegiatan seni yang masih kurang.

\section{Metode Kegiatan}

Berdasarkan hasil observasi di lapangan, maka metode yang digunakan dalam menganalisis hasil upaya pelestarian budaya melalui pagelaran seni Heman ka Budak bagi remaja dalam peningkatan kebanggaan 
budaya sunda di Kabupaten Kuningan, Jawa Barat melalui Focus Group Discussion (FGD) dengan Kepala Dinas, Kepala Bidang, Dinas Pariwisata, Dinas Pendidikan, serta Kepala Desa Karangkancana, Pengelola Kegiatan Heman Ka Budak, Kepala Sanggar Budaya, Penari/pengisi acara Heman Ka Budak sebagai implementasi pemetaan yang dilakukan.

\section{Pembahasan}

Focus Group Discussion (FGD) dilaksanakan di Gedung Kesenian Kuningan dengan dihadiri oleh sembilan orang yaitu Kabid Pendidikan dan Kebudayaan (Dodon Sugiarto.), Kepala Sie Pendidikan dan Kebudayaan (Slamet Riyadi), Staf Area (Barnas Susanto, Ehan Rohandi, lyus Ruswadi, Satuni Heryana, Narji, Ahmad Sanusi, Suhud), Seniman Lokal (Abah Deden Swaloka). Dari pihak IImu Komunikasi Universitas Bakrie dihadiri oleh Mirana Hanathasia, S.Sos., MMediaPrac. dan Ari Kurnia, M.lkom. yang bertindak sebagai moderator.

Mahasiswa Ilmu Komunikasi Meliani Nurul bertindak sebagai notulist. Pembahasan dalam FGD berkaitan dengan tidak adanya pendanaan yang memfasilitasi kegiatan Heman Ka Budak. Anggaran dari Pemda tidak diprioritaskan untuk acara kesenian dan kebudayaan. Sementara publikasi kegiatan Heman ka Budak setiap minggunya tidak melibatkan media massa lokal maupun nasional. Karena tidak adanya dana dan sponsor, maka selamai nihanya melakukan promosi kegiatan menggunakan media sosial Facebook dan Instagram, hingga pesan berantai WhatsApp.

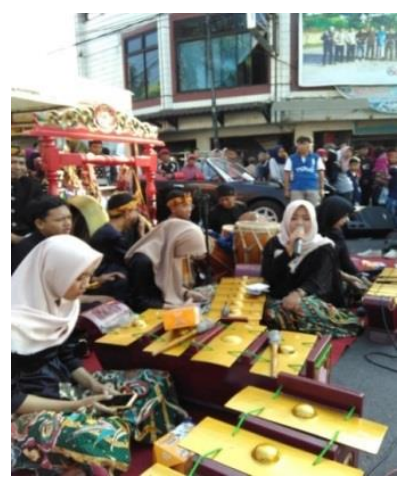

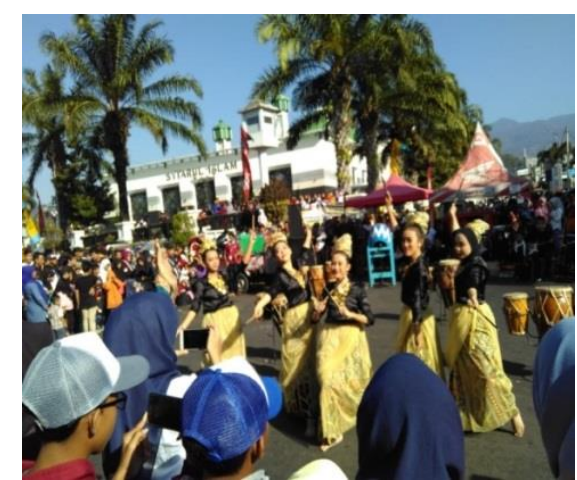

Gambar 1. Pagelaran Heman Ka Budak di Car Free Day JI. SiliwangiKab. Kuningan, Jawa Barat

(Sumber: Dokumentasi penulis)

Secara umum pelaksanaan "Heman Ka Budak" mendapatkan respon positif dari masyarakat. Para pengisi acara juga makin dikenal masyarakat. Jika di acara "Heman $\mathrm{Ka}$ Budak" para pengisi acara tidak dibayar bahkan mereka harus merogoh kocek sendiri, namun seiring dengan makin dikenalnya mereka melalui acara ini mereka diundang untuk mengisi acara ke acaraacara hajatan lokal dengan bayaran, seperti acara kawinan, sunatan dan sebagainya. "Heman Ka Budak" sendiri merupakan ruang ekspresi bagi para seniman dan budayawan lokal Kuningan.
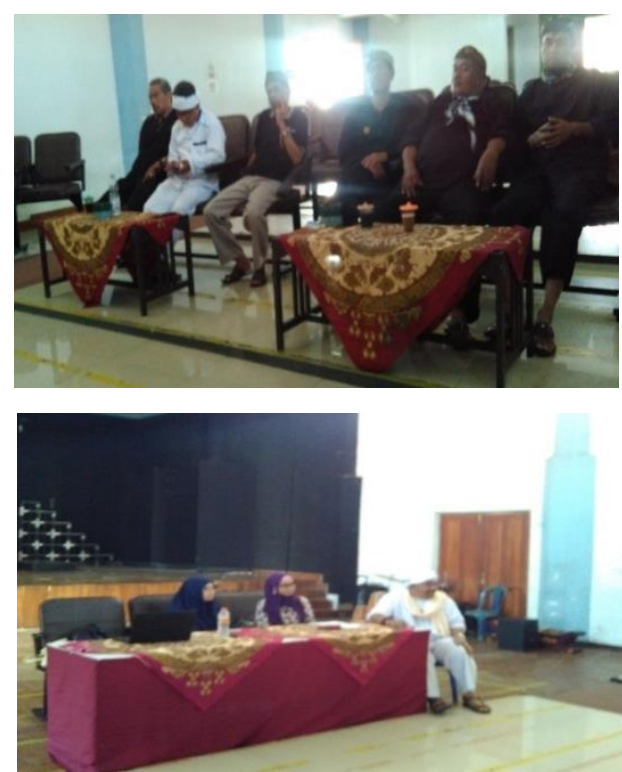

Gambar 2. FGD evaluasi dari Pemetaan Masalah Pelestarian Budaya Sunda Heman Ka Budak

(Sumber: Dokumentasi penulis) 
Melalui FGD, para peserta menyadari banyak sejumlah kendala yang menghambat masyarakat turut serta melestarikan budaya Sunda ini, seperti pemahaman penggunaan teknologi sosial media yang kurang. Mereka hanya memanfaatkan fungsi hiburan saja, tanpa memanfaatkan fungsi informasi tentang Heman Ka Budak itu sendiri. Selain itu melalui FGD, para peserta juga kesulitan memberdayaan kegiatan "Heman Ka Budak" untuk meraih donasi meski penggunaan media baru sebagai strategi memperkenalkan seni lokal telah dilakukan. Namun ini tidak mampu dilirik oleh para donatur.

Publikasi yang kurang, tidak adanya keterlibatan media massa dalam mempromosikan kegiatan ini, sehingga acara mingguan Heman ka Budak juga tidak didukung oleh sponsor baik berupa produk ataupun dana. Publikasi jelang pelaksanaan kegiatan hanya melalui media baru Facebook, Instagram dan Whatsapp. Sementara pada hari $H$ pelaksanaan, kegiatan hanya diabadikan melalui live Facebook. Semantara upaya melakukan kampanye sosial sebagai bentuk kesadaran masyarakat terhadap pelestarian budaya lokal sudah dilakukan dengan cara penyampaian informasi melalui sejumlah orasi di beberapa dinas dan tempat lainnya.

\section{Kesimpulan}

Pemetaan masalah dalam upaya pelestarian budaya lokal yaitu Heman Ka Budak melalui FGD dianggap terbuka dan menjawab banyak kendala dan kekurangan dari kegiatan ini. Meski kegiatan Heman Ka
Budak mendapat dukungan dan respon positif dari masyarakat, antusias para seniman lokal untuk mengisi acara juga tinggi. Dengan keterlibatan siswa/siswi sebagai peserta menjadi bagian dari promosi bagi generasi mereka. Dan melibatkan media massa lokal maupun nasional yang mempublikasi kegiatan ini. Hal ini terjadi karena tidak adanya dana yang mendukung kegiatan ini. Kegiatan mingguan ini berjalan masing-masing menggunakan uang pribadi dari Kepala Bidang Disdikbud dan sesekali sumbangan dari kolega.

\section{Ucapan Terima Kasih}

Terima kasih kepada Lembaga Pengabdian Masyarakat Universitas Bakrie, yang telah mendanai dan memfasilitasi untuk kegiatan PkM ini, Bapak Drs. Dodon Sugiarto selaku Kepala Bidang Budaya di Dinas Pendidikan dan Kebudayaan (Diskdikbud) Kabupaten Kuningan, serta sejumlah seniman yang terlibat dalam FGD.

\section{Daftar Pustaka}

Buchory, Achmad. 2008. Budaya. Surakarta: PT. Putra Nugraha.

Nasrullah, R. 2017. Media Sosial: Perspektif Komunikasi, Budaya, dan Sosioteknologi. Bandung: Remaja Rosdakarya

Mingkid, E. 2015. Penggunaan Media Komunikasi Promosi Pariwisata oleh Pemerintah Kota Manado. Sosiohumaniora, 18(3): 188-192.

Venus, Antar. 2012. Manajemen Kampanye. Bandung: Simbiosa Rekatama Media. 